\title{
Analytical modelling of a three-layer wall system of strengthening for large-panel slab buildings by means of bonded anchors
}

\author{
Jerzy K. Szlendak ${ }^{1}$, Agnieszka Jablonska-Krysiewicz ${ }^{1}$, and Dariusz Tomaszewicz ${ }^{2 *}$ \\ ${ }^{1}$ Faculty of Civil and Environmental Engineering, Bialystok University of Technology, Bialystok, \\ Poland \\ ${ }^{2}$ Higher School of Agribusiness in Lomza, Technical Faculty, Lomza, Poland
}

\begin{abstract}
The goal of the article is to elaboration analytical models describing a new system of reinforcing three-layer walls of large-panel buildings with bonded anchors. The use of this type of fasteners that bond the façade texture layer to the structural slab is necessary due to the low durability of previously used suspension elements. Various bonded anchorage systems were considered. The new anchorage systems were designed as two-anchors systems (horizontal anchor and diagonal anchors) and three-anchors systems (horizontal anchor and two diagonal anchors). The inclinations of these anchors are in the range of $30^{\circ}-60^{\circ}$ in relation to the surface of the element. For the above types of reinforcements, analytical models have been developed that take into account the change of strength parameters of the resin and steel from which the anchors were made, the interaction of materials resin-steel and resin-concrete and the effect of the simultaneous action of pull-out and shearing forces. Moreover, was assumed the simultaneous destruction of fasteners two- and three-anchors. The elaborated analytical models will be used to determine the load-bearing capacity of the new connector system, which will allow the elaboration of guidelines for strengthening three-layer walls of largepanel slab buildings.
\end{abstract}

\section{Introduction}

The emphasis is on the strengthening of panel buildings in Poland. Because of ends of their durability, which now exceeds 40 years. This problem will be with the passage of time and required knowledge grew as it addressed.

According to the author's main problem is not the security of the whole structure of concrete slabs but individual components. Mainly it comes to the so-called ,anchors" that is, the connecting rods with one another triple wall parts namely textured layer, a layer of insulation in the form of expanded polystyrene or mineral wool and a structural layer. The author investigates the walls tiered system of big plates OWT-67/N. Additional reinforcements are needed new anchors these walls in order to minimize the risk of

* Corresponding author: Dariusz.Tomaszewicz@poczta.wsa.edu.pl 
disruption of the cladding layer of the textured. This problem has been well-described in the Engineer Construction 1/2013 by the Appraiser of Construction Eng. Kazimierz Staszałek [1]: „Past experience operating and test results give rise to a low level of performance evaluation and installation of sandwich elements, resulting in accelerated degradation of the structure" and ,in a bad state of anchors and anchor rods outer layer with a layer of structural feared to break the connection, and thus the movement of the precast wall relative to each other." One of the main factors ensuring the proper operation of the external walls of the prefabricated building is the correct state of their connections. They are subject to external impacts, which include: the weight of the layers textured, wind, temperature variation et al. for example, the shrinkage of concrete. The aim of the publication are tested rods teaming textured layer with a layer of construction in the outer walls of buildings layer of the panel, ie. "Anchors". They are arranged in the plates in such a way as to put up as little resistance to deformation of the outer layer. The minimal number plate is 2 pieces. Accordingly, the number of anchors determined as calculated in accordance with industry standard BN-79-8812-01 (in Polish). Panels system OWT-67/N performed similarly, as in most of the panel systems in Poland, which is a layer of texture up. This was due to the fact that the textured was a lighter layer of the structural layer through which pressure was lower layer of insulation, which originally accounted for polystyrene and mineral wool later years. Initially anchors made of steel St3SX.
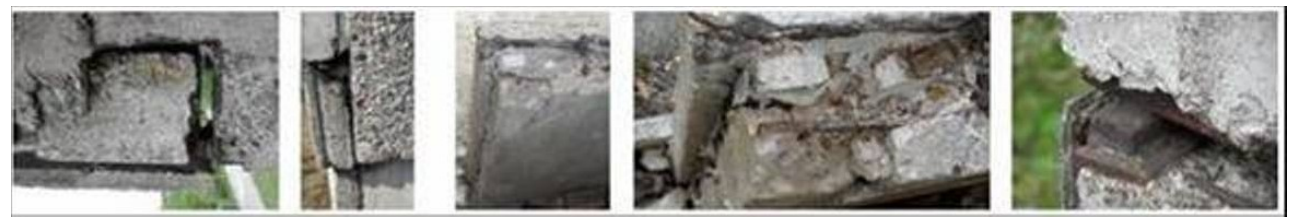

Fig. 1. Place of occurrence of defects in the outer of the three-layer walls in the OWT-67/N system.

Standard recommended the production of stainless steel anchors - class A-I species H13N4G9 according to PN-84/H-93004 (in Polish) recommended the production of stainless steel anchors - class A-I species H13N4G9 according to PN-84/H-93004 (in Polish). In addition, user acceptable except steel grade H13N4G9 also use anchors and stainless steel pins (Fig. 4) species 1H17N4G9, OH17N4G8 and OH18N9 (see the tab. 1). Summaries grade steel hangers described [2] subordinating individual steel grades selected large panel systems.

Table 1. Species used in the production of steel anchors and pins.

\begin{tabular}{|c|c|c|c|}
\hline Type of steel & $\begin{array}{c}\text { Tensile strength } \\
\mathbf{R} \mathbf{m}[\mathbf{M P a}]\end{array}$ & $\begin{array}{c}\text { The yield strength } \mathbf{R}_{\mathbf{e}} \\
{[\mathbf{M P a}]}\end{array}$ & $\begin{array}{c}\text { Elongation at break } \\
\text { As [\%] }\end{array}$ \\
\hline H13N4G9 & 650 & 350 & 35 \\
\hline 1H17N4G9 & 650 & 310 & 40 \\
\hline OH17N4G8 & 530 & 280 & 40 \\
\hline OH18N9 & 500 & 200 & 45 \\
\hline
\end{tabular}

Anchors (fig. 2 and fig. 3) loop shape formed similar to a triangle and carried them out of steel rods which have passed through all the layers of the slab. Cooperate with mesh reinforcement plates by using the anchorage through basic transverse bars. Shapes anchors and guidelines for their use presented in the book [3] and in the article [4, 5]. The number and location of anchors in the slab should provide load capacity enabling security carrying 
the weight of the facing layer to the inner layer of textural wall design while maintaining the freedom of deformation.

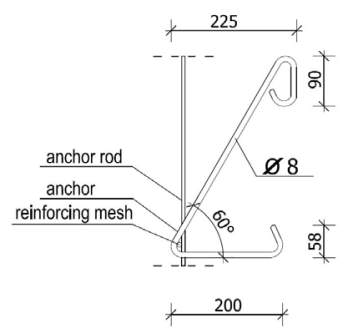

Fig. 2. The shape of the anchor that was used in the production of three-layer in the OWT-67/N system to the end of the $70 \mathrm{~s}$ of the twentieth century.

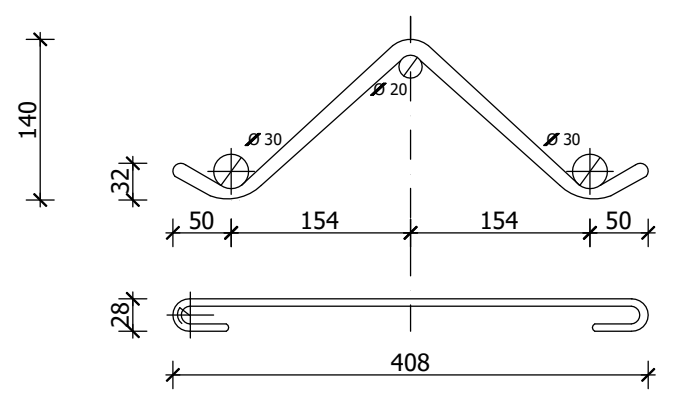

Fig. 3. Anchor type of 2.05 used in the gable in the new OWT-67 system.

Pins (fig. 4) were made of steel wire with a diameter of 3.0 to $4.5 \mathrm{~mm}$ and bent into the shape of an elongated "U". Pins were placed around the perimeter of panels and around openings in number from a dozen to several dozen pieces. Their task was to stabilize the outer layer of the textured and counteracting the effects of the load from wind suction forces.

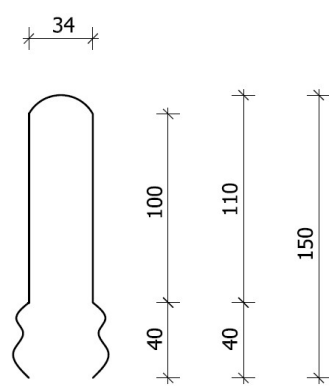

Fig. 4. Pins used peripherally in the wall sandwich panels.

Additionally, in some cases, anchors were additionally protected with a corrosion protective coating such as latex coating. The durability of steel of which were made anchors and corrosion protection significantly lengthened the process of degradation of these connections, which minimize the risk of falling off layers of texture. A textured layer made of reinforced concrete class $\mathrm{C} 12 / 15$ and a minimum of $5 \%$ water absorption. Forming panels should provide reinforcement and stabilization of anchors. The required minimum buffer zone of mesh should be $25 \mathrm{~mm}$ and the anchors in place of the bend minimum of 15 $\mathrm{mm}$. In designing the plate impact of aggressive environmental impact assessments on 
anchors rods of stainless steel ordinary evaluated relatively high. Durability anchor made of ordinary steel was estimated in the range of 20 to 40 years.

\section{Methods for determining the capacity of bonded anchor pull- out and shear}

The first stage of the new anchorage load tests to check their capacity to pull-out. The research of capacity on pull-out carry out among other [6-13]. This is done in two stages. In the first stage are checked hydraulic cylinder or horizontal anchorage tester, and then by using the device in the form of a frame are checked oblique anchoring. Examples of the destruction of bonded anchoring fixings in concrete, which may occur during the testing capacity of the anchor pull-out shown in Fig. 5 - Fig. 8. For the tests conducted by the author is certainly not a case of steel failure occurs (Fig. 5) as a substrate in a textured layer or structural layer is made of a too low-class concrete.

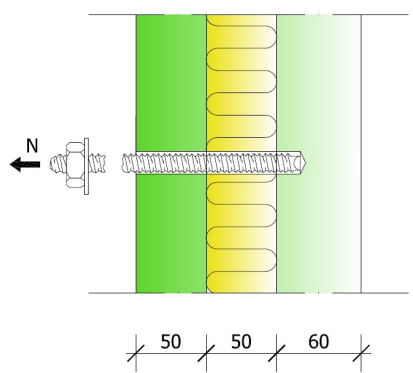

Fig. 5. Steel failure by of breaking mandrel anchor.

Due precisely to the class of concrete usually, the case with the destruction of attachment anchors to concrete substrate adhesion resistance of the resin, which is material to bond with the concrete anchor is pulling concrete cone (Fig. 6).

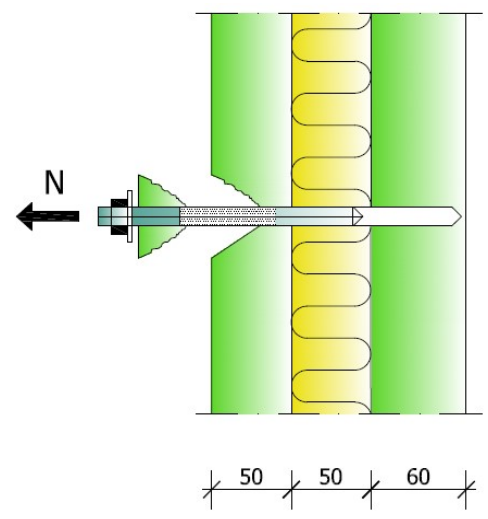

Fig. 6. The destruction of the anchorage due to pull-out failure (bond failure) the anchor.

The situation in which the cleavage occurs in the concrete may occur if it is a too deep hole drilled in relation to the length of the anchor. The occurrence of the last case, that the destruction of the anchorage in the concrete as a result of extraction (Fig. 7) the author (D. Tomaszewicz) obtained in their own research. 


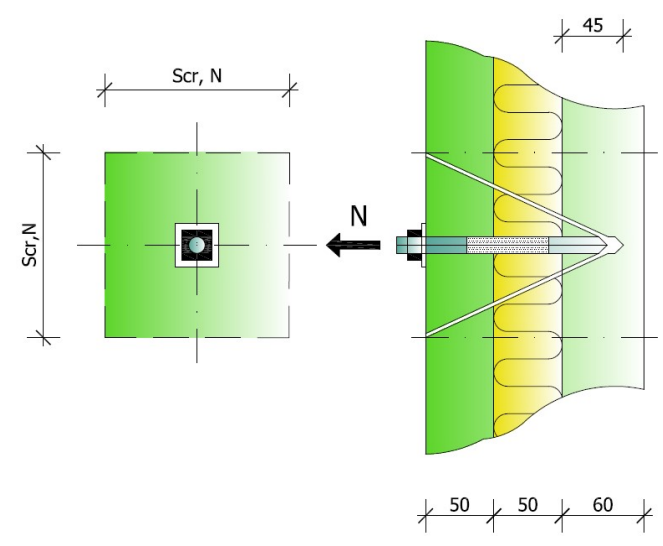

Fig. 7. The destruction of the anchorage due to break out concrete cone concrete cone failure.

Splitting failure (Fig. 8) is avoided during anchor installation by complying with minimum values for edge distance $c_{\min }$, spacing $s_{\min }$, member thickness $h_{\min }$ and reinforcement as given in the relevant ETA. For splitting failure due to loading the values $\mathrm{c}_{\mathrm{cr}, \mathrm{sp}}$ and $\mathrm{s}_{\mathrm{cr}, \mathrm{sp}}$ shall be taken from the ETA as a function of the embedment depth. The destruction occurred due to the improper or inadequate cleaning of the hole after drilling. In the case of research on the shear capacity of anchorages most probable destruction of attachment anchors with concrete is breaking off the edge of the concrete (Fig. 9). This failure mechanism occurs when the direction of the shear force is oriented towards the edge of the concrete at a minimum distance from the edge. It is also possible for instance due to the destruction of the embedment of the anchor of breaking the concrete edge failure (Fig. 10).

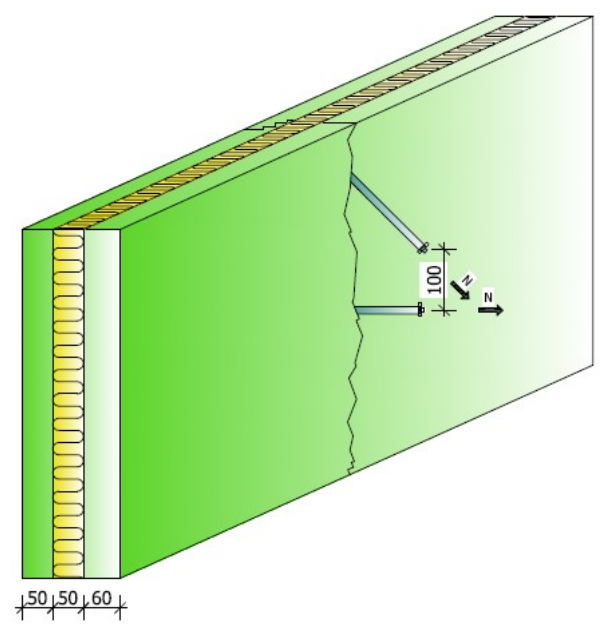

Fig. 8. The destruction of mounts anchors due to splitting failure.

However, it must be ordered to anchor a fairly large force. The case of destruction by breaking the edge of the concrete can be obtained in further research. 


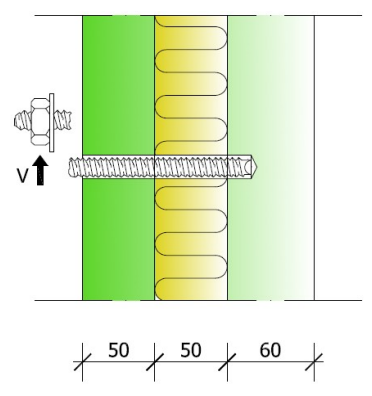

Fig. 9. Steel failure by the destruction of mounts due to shear mandrel anchor.

The greatest probability of its occurrence will occur in a designed diagonal twoanchorages system with an anchor system at an angle of $30^{\circ}$, located along the long edge (at a distance of $5 \mathrm{~cm}$ on both sides) in samples with dimensions of $40.0 \times 20.0 \times 17.0 \mathrm{~cm}$.

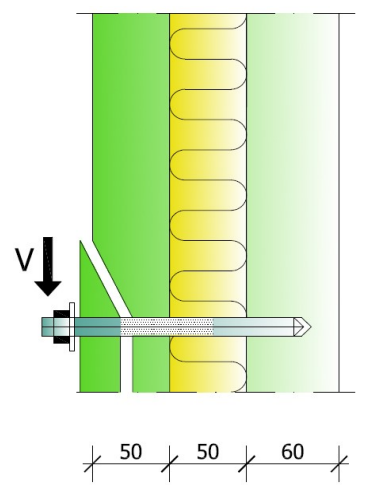

Fig. 10. The destruction of Mounts a result of breaking the concrete edge failure.

The last accident that may occur in the course of testing the shear capacity of the anchor is breaking concrete by concrete pry-out failure (Fig. 11). The effect of such destruction can occur only in the case of a group of anchors, combined together, such as a flat bar. The resulting effect of destruction of this type of attachment is interactive in nature since in this case the load capacity of the phenomena join anchor pull-out and shear. The shear force results in the following turnover of anchors with nature lever.

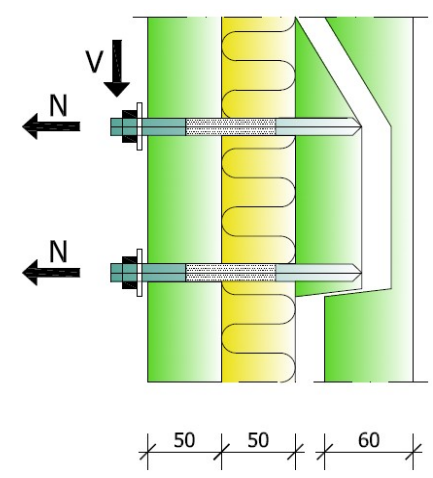

Fig. 11. The destruction of mounts due to destruction by concrete pry-out failure.

Patterns and guidelines for computation capacity of anchor pull-out and shear (Fig. 5 Fig. 11) are included in the Guidelines for European Technical Approval TR 023 and TR $029[14,15]$, and in the Technical Specifications given in the literature [16-18]. 


\section{Variants of reinforcement of three-layer wall}

\subsection{Two-anchorages system based on the COPY-ECO system}

There are a lot of system anchors on the Polish market. A number of companies offer their solutions. Each of the solutions leads to strengthening the adhesion of the textured layer to the insulation layer and the construction layer. The problem is to estimate the durability of these fixings. Therefore, attempts are made to pull out anchorages for individual systems. An interesting solution is anchoring a leading company in Poland called COPY-ECO, which imitates the shape and work of a hanger that joins three-layer walls. Changing the settings of diagonal anchors is related not only to the thicknesses of three-layer walls but also to the stress distribution during the tests of anchorage capacity of anchorages. It is also necessary to take into account the load-bearing capacity of the anchors on the wall due to the "slipping" of the vertical textured layer.

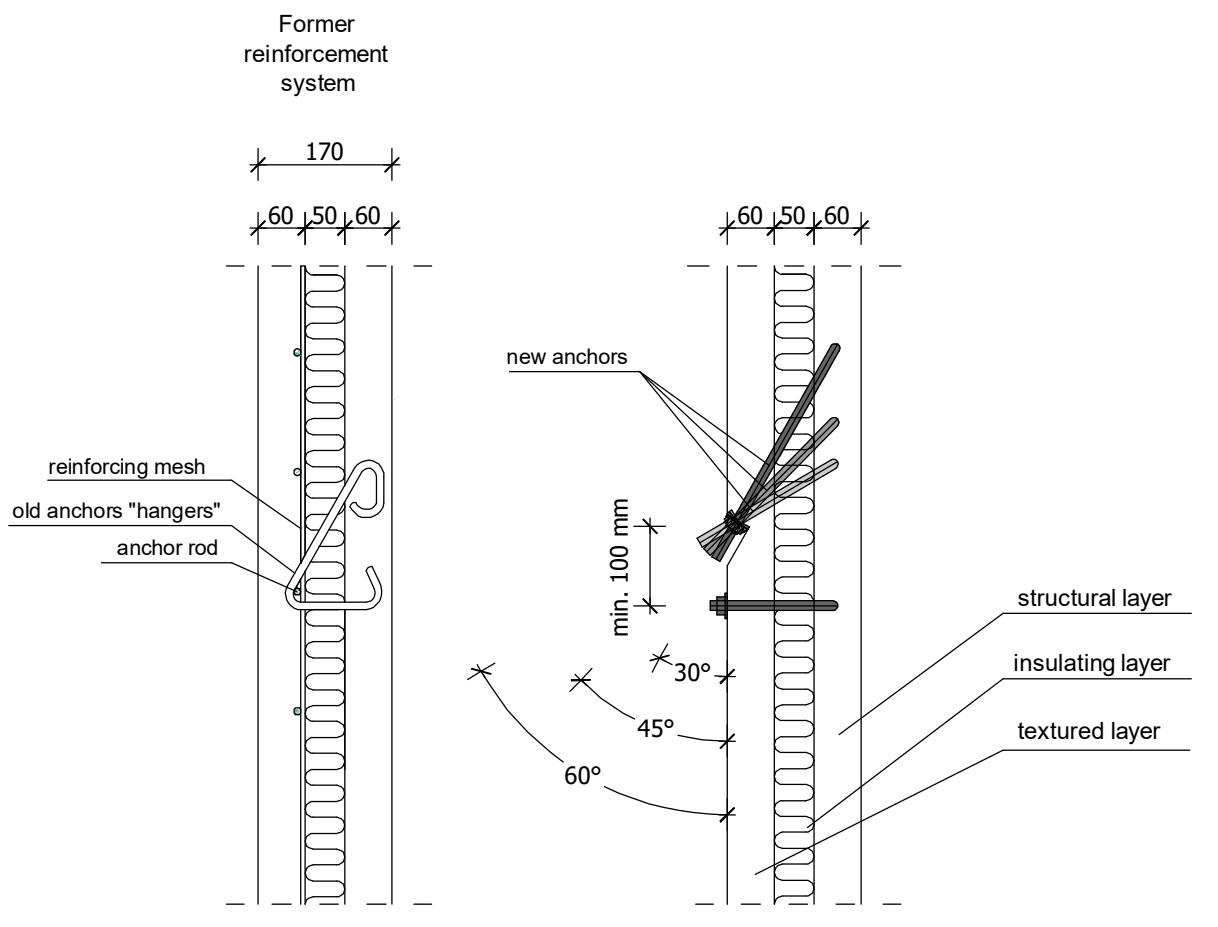

Fig. 12. Scheme anchor used to the end of the 70 s of the last century and a proposal for new anchorages along the lines of COPY-ECO system

It has been proposed that additional anchors with variable angular settings be modelled on this system. The idea of changing the angles of inclination of the diagonal anchors came from the fact that the hangers were bent. The use of such anchorages will allow a wider range of tests on their bearing capacity and durability. 
An analytical model of a two-anchorages system:

$$
P=\left\{\begin{array}{l}
c \cdot\left[\pi \cdot r \cdot\left(\sqrt{r^{2}+h_{e f}^{2}}\right) \cdot 0,866-\left(\pi \cdot d \cdot h_{\text {ef }} \cdot c+\pi \cdot d \cdot h_{\text {ef }} \cdot b\right)+c \cdot\left[\pi \cdot r \cdot\left(\sqrt{r^{2}+h_{e f}^{2}}\right)\right] \cdot 0,7071-\right. \\
\left(\pi \cdot d \cdot h_{\text {ef }} \cdot c+\pi \cdot d \cdot h_{\text {ef }} \cdot b\right)+c \cdot\left[\pi \cdot r \cdot\left(\sqrt{r^{2}+h_{\text {ef }}^{2}}\right)\right] \cdot 0,50-\left(\pi \cdot d \cdot h_{\text {ef }} \cdot c+\pi \cdot d \cdot h_{\text {ef }} \cdot b\right)+c \cdot\left[\pi \cdot r \cdot\left(\sqrt{r^{2}+h_{\text {ef }}^{2}}\right)\right]- \\
\left(\pi \cdot d \cdot h_{\text {ef }} \cdot c+\pi \cdot d \cdot h_{\text {ef }} \cdot b\right)
\end{array}\right\}
$$

where:

$\mathrm{P}$ - maximum breaking force; $\mathrm{N}$

$c$ - adhesion strength resin - concrete, $\mathrm{N} / \mathrm{mm}^{2}$

$\mathrm{r}$ - the radius of the cone, $\mathrm{mm}$

$\mathrm{h}_{\mathrm{ef}}$ - anchor depth of the anchor in concrete, $\mathrm{mm}$

$\mathrm{d}$ - hole diameter, $\mathrm{mm}$

$\mathrm{b}$ - adhesive strength resin - steel anchor, N/mm ${ }^{2}$

The simultaneous occurrence of all the effects of diagonal anchors is a theoretical assumption which is subject to a practical check in terms of durability of new anchorages.

\subsection{Three-anchorages system as a mirror image of the COPY-ECO system}

The three- anchorages system was designed following the shape of a hanger used in largepanel construction in the $1980 \mathrm{~s}$.

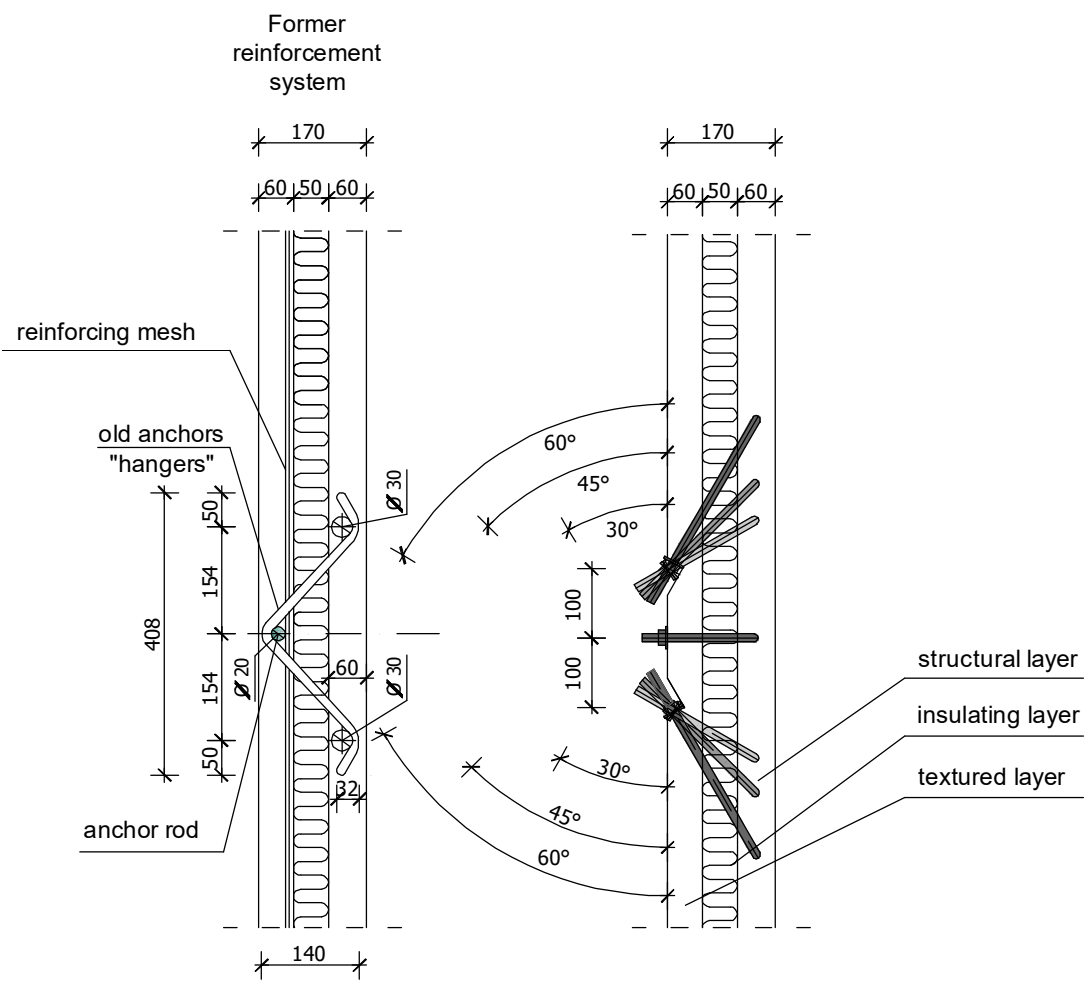

Fig. 13. Schematic anchoring anchor in a "V" and the proposal of new anchorages 
An analytical model of a three-anchorages system:

$$
\begin{aligned}
& \mathrm{P}=2 \cdot\left\{\begin{array}{l}
\mathrm{c} \cdot\left[\pi \cdot \mathrm{r} \cdot\left(\sqrt{\mathrm{r}^{2}+\mathrm{h}_{\mathrm{ef}}^{2}}\right)\right] \cdot 0,866-\left(\pi \cdot \mathrm{d} \cdot \mathrm{h}_{\mathrm{ef}} \cdot \mathrm{c}+\pi \cdot \mathrm{d} \cdot \mathrm{h}_{\mathrm{ef}} \cdot \mathrm{b}\right)+\mathrm{c} \cdot\left[\pi \cdot \mathrm{r} \cdot\left(\sqrt{\mathrm{r}^{2}+\mathrm{h}_{\mathrm{ef}}^{2}}\right) \cdot 0,7071-\right. \\
\left(\pi \cdot \mathrm{d} \cdot \mathrm{h}_{\mathrm{ef}} \cdot \mathrm{c}+\pi \cdot \mathrm{d} \cdot \mathrm{h}_{\mathrm{ef}} \cdot \mathrm{b}\right)+\mathrm{c} \cdot\left[\pi \cdot \mathrm{r} \cdot\left(\sqrt{\mathrm{r}^{2}+\mathrm{h}_{\mathrm{ef}}^{2}}\right) \cdot 0,50-\left(\pi \cdot \mathrm{d} \cdot \mathrm{h}_{\mathrm{ef}} \cdot \mathrm{c}+\pi \cdot \mathrm{d} \cdot \mathrm{h}_{\mathrm{ef}} \cdot \mathrm{b}\right)\right.
\end{array}\right\}+\mathrm{c} \cdot\left[\pi \cdot \mathrm{r} \cdot\left(\sqrt{\mathrm{r}^{2}+\mathrm{h}_{\mathrm{ef}}^{2}}\right)\right]- \\
& \left(\pi \cdot \mathrm{d} \cdot \mathrm{h}_{\mathrm{ef}} \cdot \mathrm{c}+\pi \cdot \mathrm{d} \cdot \mathrm{h}_{\mathrm{ef}} \cdot \mathrm{b}\right)
\end{aligned}
$$

\section{Conclusions}

There is no doubt that three-layer walls in large-panel buildings should be repaired or strengthened due to the dubious durability of the façade of the textured layer. One of the ways is to ensure the mapping of the system of former anchorages. This is guaranteed by the COPY-ECO system. There is a possibility of a variant strengthening of the textured layer in three-layer walls, related to the change in the angle of anchors. This article considers the possibility of using such anchorages due to the varied condition of the façade of the textured layer. The final stage of reinforcing works, i.e. fixing anchorages glued in three-layer walls, is thermo-modernization of these objects.

The paper was prepared at Bialystok University of Technology within a framework of the S/WBiIŚ/2/2017 project sponsored by Ministry of Science and Higher Education.

\section{References}

1. K. Staszałek, Problems large panel reinforcements before thermomodernisation, Construction Engineer 1/2013, 86-88. (in Polish), (2013)

2. M. Wojtowicz, Fault hazard of façade sandwich panels in the buildings constructed by means of large panel technology - real problem or media hit, XXV Scientific Technical Conference $24-27$ May ,Building failures, 533-542. (in Polish) Miedzyzdroje, (2011)

3. W. Starosolski, Z. Dzierzewicz, Systems of constructions with large slabs in Poland in the years 1970-1985. Overview of material solutions, technology and constructional, Publishing a Wolters Kulwer business, 121-128. (in Polish) Warsaw, (2010).

4. A. Krysiak, K. Regulska ,The repair methods of technological defects of external layered cavity walls during thermo modernization in prefabricated buildings, Publisher University of Czestochowa, 116-125 (in Polish), (2012)

5. N. Rasidi, M. D. Soehardjono, A. Zacoeb ,Cracking Behavior in Precast Deck Slab Concrete Structure under Cyclic Loading, International Journal of Engineering and Technology Volume 3 No. 8, August, (2013)

6. R. Eligehausen, W. Fuchs, T. M. Sippel (1998) ,Anchorage to concrete, Structural Engineering and Materials, Vol. 1(4), 392-403

7. J. A. Bickley (1981), Pullout testing of concrete. Cast-in-place device enables concrete to be evaluated in the structure with only minor damage, Consulting Engineers.

8. R. Ballarini, S. P. Shah, L. M. Keer (1986), Failure characteristics of shot anchor bolts embedded in a brittle material, Proceedings of the Royal Society of London A 404, 35 54.

9. M. Ghandehari, S. Krishnaswamy, S. Shah (2000) ,Bond-Induced Longitudinal Fracture in Reinforced Concrete, Journal of Applied Mechanics, Vol. 67, 740-748, December 2000. 
10. T. A. Weigel, J. P. Mohsen, A. Burke, K. Erdmann, A. Schad ,Tensile Strength of Headed Anchor Bolts in Tops of Fully Grouted Concrete Masonry Walls, TMS Journal, 61-70, December 2002.

11. H. Sato, K. Fujikake, S. Mindess (2004), Study on dynamic pullout strength of anchors based on failure models, $13^{\text {th }}$ World Conference on Earthquake Engineering Vancouver, B.C., Canada August 1-6, 2004. Paper No. 854.

12. O. Ch. Choi (2004), Roles of Bearing Angle in Bond Action of Reinforcing Bars to Concrete, Journal of the Korea Concrete Institute, Vol. 16, No. 5, 719-724.

13. J. C. Gálvez, J. M. Benítez, M. J. Casati, B. S. Tork., D. A. Cendón (2011) ,Cohesivefrictional model for bond and splitting action of prestressing wire, International Journal for Numerical and Analytical Methods in Geomechanics, Vol. 35, Issue 11, 1257-1277, 10 August 2011.

14. EOTA. Technical Report 023 ,Assessment of post-installed rebar connections, Edition November, (2006)

15. EOTA. Technical Report 029 ,Design of Bonded Anchors, Edition June, (2007)

16. DD CEN/TS 1992-4-1:2009, Design of fastenings for use in concrete. Part 4-1: General, British Standards Institution, (2009)

17. DD CEN/TS 1992-4-3:2009, Design of fastenings for use in concrete. Part 4-3: Anchor channels, British Standards Institution, (2009)

18. DD CEN/TS 1992-4-5:2009, Design of fastenings for use in concrete. Part 4-5: Chemical systems, British Standards Institution, (2009) 